\title{
Mitral valvotomy in childhood
}

\author{
M. S. GOTSMAN ${ }^{1}, R$. L. VAN DER HOR ST, B. T. le ROUX, and \\ M. A. W I L L I A M S
}

\begin{abstract}
Cardio-Thoracic Unit, Wentworth Hospital and the Departments of Medicine and Surgery, University of Natal, South Africa
\end{abstract}

\begin{abstract}
Gotsman, M. S., van der Horst, R. L., le Roux, B. T., and Williams, M. A. (1973). Thorax, 453-457. Mitral valvotomy in childhood. During the seven-year period 1965 to 1972 mitral valvotomy for mitral stenosis was undertaken in 72 children aged 15 years or less. Excellent results were achieved from closed transventricular instrumental valvotomy unless the valve was calcified, there was a jet of mitral incompetence or a second valvotomy was being undertaken. Severe pulmonary arterial hypertension was present before operation and regressed after a successful valvotomy. There was a low incidence of overt antecedent rheumatic fever.
\end{abstract}

Mitral valvotomy is a good operation for the relief of pure, critical mitral stenosis when the valve cusps are pliable and not calcified (Turner and Fraser, 1956 ; Ellis, Harken, and Black, 1959 ; Logan, Lowther, and Turner, 1962 ; Kitchin and Turner, 1967 ; Turner, 1967).

In many countries the incidence of acute rheumatic fever has declined, and established valvular disease is now rare in the paediatric age group. In Natal, in the Republic of South Africa, acute rheumatic fever is still endemic and established mitral valve disease is common in childhood and adolescence.

The purpose of this paper is to report a series of 72 patients, judged to have had severe mitral valvular obstruction, who were submitted to transventricular dilatation of the mitral valve (Logan et al., 1962) and, from this experience with children, to try to determine if the disease is more severe in childhood, if there are special diagnostic problems, if pulmonary arterial hypertension is more severe, if closed mitral valvotomy is a suitable operation for mitral stenosis in children, and if the results of operation are rewarding in the presence of calcification of the valve or in the presence of a small jet of associated mitral incompetence.

\section{THE PATIENTS}

Closed transventricular mitral valvotomy was performed in 510 patients with severe mitral stenosis

1Address for reprints: Professor M. S. Gotsman, Cardiac Unit, Wentworth Hospital, P. B. Jacobs, Natal, South Africa
T A B LE I

AGE, SEX, AND RACIAL INCIDENCE

\begin{tabular}{llr}
\hline Age (yr) & $0-5$ & 1 \\
& $6-10$ & 22 \\
Sex & $11-15$ & 49 \\
& Male & 28 \\
Race & Female & 44 \\
& White & 1 \\
& Coloured & 2 \\
& Asiatic & 16 \\
& African & 53 \\
\hline
\end{tabular}

during the seven-year period 1965-72. Seventy-two of these patients were 15 years of age or younger and have been selected for special study. The age range is shown in Table $I$. Half the patients were 12 to 15 years old and the youngest was 5 years. Twothirds were female. Three-quarters were African and one-quarter were Asiatic. The incidence was negligible in the Coloured and Caucasian population and this is in striking contrast to the racial incidence of all patients seen during the same period.

CLINICAL PICTURE The patients presented with dyspnoea on exertion; they were grade IIB-IV disabled (classification of the American Heart Association), often with a history which extended over a year or two only. The history could not be analysed in detail since the children and their parents were often unable to date the history and the duration of symptoms. Only two gave a history of antecedent acute rheumatic fever. Nine had been frightened by the severity of haemoptysis. Two older patients in this series were in atrial fibrillation. The mitral valve alone was affected in two-thirds of the patients. Onethird also had important tricuspid incompetence, which was usually functional and a consequence of severe pulmonary hypertension. Six patients with 
severe mitral stenosis had such significant additional tricuspid incompetence that the right ventricle formed the apex of the heart and the tricuspid systolic murmur did not vary with respiration and radiated to the axilla. In most patients the volume of tricuspid incompetence decreased with bedrest, digitalis, and diuretic therapy, but in five it was difficult to exclude a jet of mitral incompetence on clinical grounds.

The clinical features were not peculiar to childhood. Severity of mitral valve obstruction could be assessed from the usual criteria-the length of the diastolic murmur, an early opening snap, delay in the onset of the first heart sound and the severity of associated pulmonary arterial hypertension as assessed by palpable right ventricular enlargement, loud pulmonary valve closure, and right ventricular hypertrophy electrocardiographically and radiologically.

Cardiac catheterization and selective angiocardiography were undertaken in 37 patients before operation to assess the degree of mitral stenosis, to demonstrate a jet of mitral incompetence, and to measure the pulmonary artery pressure in order to be able to correlate this with the clinical features and findings at operation. In nine patients cardiac catheterization was repeated before the patient left hospitalin two because they had mixed mitral valve disease, in one with severe calcific stenosis, and in the remainder to assess the extent of relief afforded by mitral valvotomy and the degree of regression of pulmonary arterial hypertension. In one postoperative study the data were incomplete. Nine patients were studied three months or longer after operation; in five this was an elective study to assess improvement in the pulmonary vascular state and, in the remaining four, to reassess an apparently inadequate clinical response to operation.

The mitral valve was calcified in nine patientsheavily in six and lightly in three. In five of these there was a jet of mitral incompetence. In 12 patients, in whom the valve was not calcified, there was also a jet of mitral incompetence as assessed by a pansystolic murmur at the apex, left ventriculography or digital exploration of the mitral valve at the time of valvotomy.

\section{RESULTS}

OPERATIVE MORTALITY (Fig. 1) Two patients died in early convalescence. The first was a 12-year-old girl with mitral stenosis and important tricuspid incompetence. She had been incapacitated for one year before valvotomy. Catheterization showed a mean pulmonary artery pressure of $85 \mathrm{mmHg}$, a pulmonary capillary wedge pressure of $32 \mathrm{mmHg}$, and a mitral diastolic gradient of $30 \mathrm{mmHg}$; PVR/SVR was $60 \%$. The valve was heavily calcified and there was a small jet of mitral incompetence. At valvotomy the valve admitted only the nail of the index finger and valvotomy was incomplete. Cardiac catheteriza-

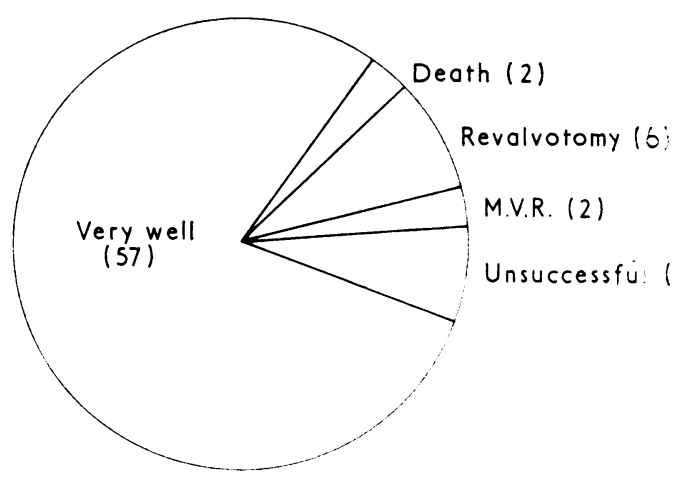

FIG. 1. Clinical outcome of 72 patients who underwent mitral valvotomy $(M V R=$ mitral valve replacement $)$.

tion performed 10 days after operation showed a mean PA pressure of $73 \mathrm{mmHg}$, a mean pulmonary capillary wedge pressure of $30 \mathrm{mmHg}, \overrightarrow{0}$ a mitral diastolic gradient of $15 \mathrm{mmHg}$, and PVR/ SVR of $61 \%$ with important mitral incompetence. She died eight days later in severe progressive cardiac failure and necropsy showed that the valve was heavily calcified, valvotomy had been⿳亠丷厂 incomplete, the chordae to the posterior leaflet⿱亠 had ruptured, and the muscular pulmonary arteries showed grade 3 histological changes $\overline{\overline{0}}$ (Harris and Heath, 1962).

The second patient was a girl aged 12 who had been grade III disabled before operation. The mitral valve was heavily calcified and she hadf additional tricuspid incompetence. The valve accepted the tip of the nail of the index finger and valvotomy was complete. She died 24 hours after valvotomy, and a large antemortem thrombus in the right atrium was found to occlude the tricuspid valve.

CALCIFIC MITRAL STENOSIS Nine patients, aged 10 to 15 years, had calcification of the mitraE. valve. This was heavy in six and light in three. The $\widetilde{\sigma}$ outcome is shown in Table II. Only two patientso had a complete valvotomy.

T A B L E I I

$\frac{\text { CALCIFIC MITRAL STENOSIS }}{2 \text { Complete valvotomies }}$

\begin{tabular}{|c|c|c|}
\hline $\begin{array}{l}\text { Heavy calcification } \\
\text { Deaths } \\
\text { Late valve replacement } \\
\text { Residual disease } \\
\text { Good valvotomy }\end{array}$ & $\begin{array}{l}2 \\
1 \\
2 \\
1\end{array}$ & 6 \\
\hline $\begin{array}{l}\text { Light calcification } \\
\text { Mild MI } \\
\text { Good valvotomy }\end{array}$ & $\begin{array}{l}2 \\
1\end{array}$ & 3 \\
\hline
\end{tabular}


Six patients had heavy calcification of the valve; two died after operation in the circumstances which have been described. Three patients have residual disease; one subsequently needed valve replacement and two are still significantly symptomatic because of mitral valve disease. One patient only is well. In patients with mitral stenosis and heavy valve calcification the results of closed valvotomy are so unsatisfactory that it is now policy to undertake elective valve replacement.

Three patients had light calcification and only one had a good valvotomy. Two have residual mitral incompetence. Any valve which is calcified should be regarded with suspicion as calcification is usually evidence of severe disease with extensive fibrosis and distortion of the valve cusps which render the valve unsuitable for a conservative procedure.

MITRAL STENOSIS WITH A SIGNIFICANT JET OF INCOMPETENCE Twelve patients had mitral stenosis with a noncalcified pliable valve and a jet of mitral incompetence (Table III). Preoperative catheterization was undertaken in 10 patients.

The results in this group also have not been satisfactory. Six patients had a good clinical response; two do not have the murmur of mitral incompetence, and the other four have mitral incompetence but are symptomatically improved. Of the remaining six patients, five have mitral incompetence and a large heart, while in the sixth patient valve replacement has been necessary.

T A B LE II I

NONCALCIFIC MITRAL STENOSIS-JET OF MITRAL INCOMPETENCE; 12 PATIENTS

\begin{tabular}{lc}
\hline Severity & 2 \\
Mild & 10 \\
Moderate & \\
Outcome & 2 \\
No clinical MI & 4 \\
Good with MI & 5 \\
Large hearts, few symptoms & 1 \\
\hline Late valve replacement & \\
\hline
\end{tabular}

MITRAL RESTENosis Mitral restenosis has occurred in 10 patients during the seven-year period under discussion. Three have clinical restenosis but are not disabled and do not need a second operation at present.

Six patients have undergone a second valvotomy: this was undertaken after a year in one patient who had an inadequate first operation; three patients have thick, immobile, furled cusps and have been judged unsuitable for a third valvotomy; one has mixed mitral valve disease ; and only one is well after the second operation. The mean interval between the two valvotomies was two years.

Young patients who early develop mitral restenosis should be submitted to an open operation at which valve replacement will almost certainly be necessary when restenosis occurs. The valve is often heavily fibrosed and unsuitable for a second closed valvotomy.

CLINICAL RESPONSE TO SURGERY The clinical response to mitral valvotomy in the 41 remaining patients was gratifying; symptoms improved, dyspnoea disappeared, and the signs of tricuspid incompetence and pulmonary arterial hypertension receded. Electrocardiographic evidence of right ventricular hypertrophy disappeared and the heart size decreased in patients who had had a large heart before operation. It is noteworthy that only one patient had Kerley B lines before operation.

\section{HAEMODYNAMIC STUDIES}

PREOPERATIVE PULMONARY HYPERTENSION Patients with mitral stenosis in childhood had severe pulmonary hypertension. The relationship between

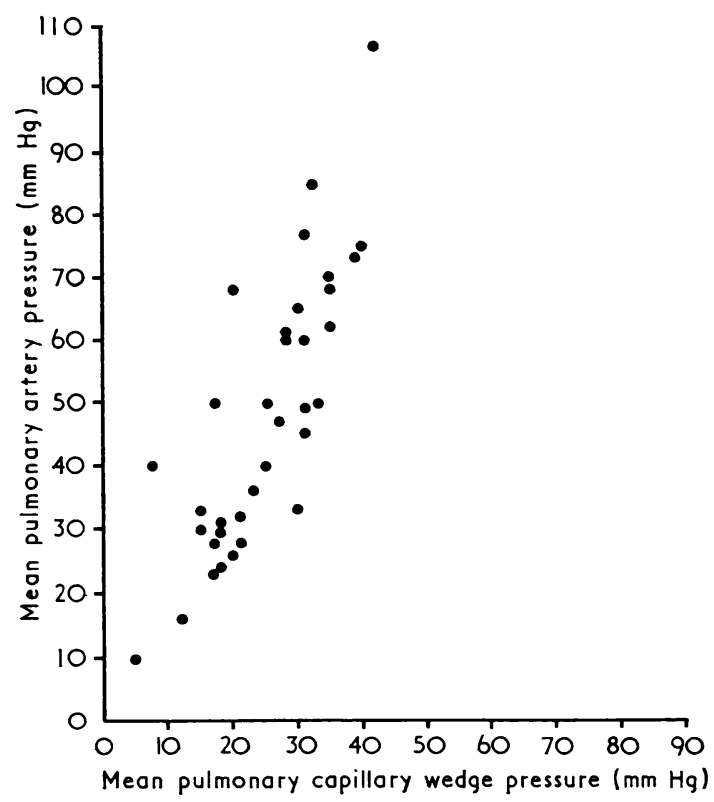

FIG. 2. Relationship between pulmonary artery and mean pulmonary capillary wedge pressure before operation in patients with juvenile mitral stenosis. Severe pulmonary hypertension was noteworthy. No patient had an elevated left ventricular end-diastolic pressure so that PCWP reflected the degree of mitral valve obstruction. 
T A B LE I V

HAEMODYNAMIC STUDIES BEFORE AND AFTER VALVOTOMY

\begin{tabular}{|c|c|c|c|c|}
\hline & \multicolumn{2}{|c|}{$\begin{array}{c}\text { Patients Studied } 0-3 \mathrm{mth} \\
\text { after Operation }\end{array}$} & \multicolumn{2}{|c|}{$\begin{array}{c}\text { Patients Studied } 4-24 \mathrm{mth} \\
\text { after Operation }\end{array}$} \\
\hline & Preop. & Postop. & Preop. & Postop. \\
\hline $\begin{array}{l}\text { Mean pulmonary artery pressure (mmHg) } \\
\text { Mean pulmonary capillary wedge pressure (mmHg) } \\
\text { Mitral diastolic gradient (mmHg) } \\
\text { Pressure gradient across pulmonary vascular bed (mmHg) } \\
\text { Pulmonary/systemic vascular resistance }(\%) \\
\text { Cardiac index }\left(1 / \mathrm{min} / \mathrm{m}^{2}\right)\end{array}$ & $\begin{array}{l}54 \pm 14 \\
26 \pm 7 \\
15 \pm 8 \\
24 \pm 10 \\
29 \pm 11 \\
2 \cdot 8 \pm 1 \cdot 2\end{array}$ & $\begin{array}{l}35 \pm 13 \\
16 \pm 7 \\
10 \pm 4 \\
16 \pm 12 \\
17 \pm 13 \\
3 \cdot 6 \pm 1 \cdot 0\end{array}$ & $\begin{array}{l}45 \pm 17 \\
26 \pm 8 \\
21 \pm 6 \\
19 \pm 10 \\
21 \pm 9 \\
4 \cdot 4 \pm 1 \cdot 9\end{array}$ & $\begin{array}{l}21 \pm 7 \\
14 \pm 2 \\
9 \pm 3 \\
7 \pm 5 \\
9 \pm 4 \\
4 \cdot 3 \pm 1 \cdot 4\end{array}$ \\
\hline
\end{tabular}

mean pulmonary artery pressure and pulmonary capillary wedge pressure (PCWP) is shown (Fig. 2). The relationship was linear until PCWP reached a level of $20 \mathrm{mmHg}$, a consequence of a passive rise in arterial pressure ; thereafter there was severe vasoconstriction and a rapid rise in arterial pressure. The degree of pulmonary arterial hypertension was related to the pulmonary capillary wedge pressure and the degree of mitral stenosis and was not significantly different from that of a comparable group of adult patients. The cardiac index was normal in this group.

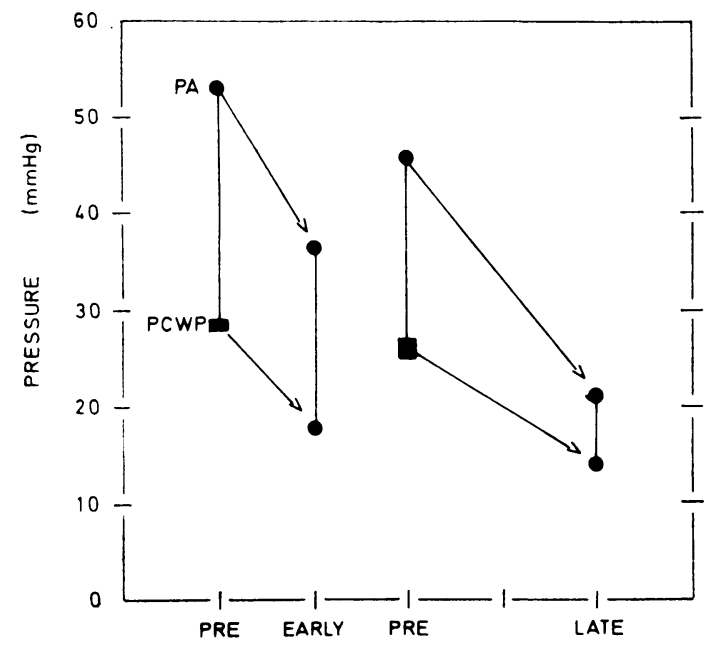

FIG. 3. Pulmonary arterial and pulmonary capillary wedge pressure in patients studied before and after mitral valvotomy. 'Early' indicates patients studied 0 to 3 months after valvotomy and 'Late' indicates patients studied 4 months to 2 years after valvotomy. There was a striking fall in pulmonary arterial $(P A)$ and pulmonary capillary wedge pressures (PCWP). This occurred immediately after surgery and there was a further fall in the late postoperative period.

EARLY POSTOPERATIVE STUdIES Nine patients were studied 12 days to three months after operation; they could be divided into two groups.
Three were investigated for another reason-a $\stackrel{\infty}{\infty}$ heavily calcified valve or mitral incompetenceand their clinical outcome was unsatisfactory ; the cf other six were studied electively to assess the result of operation. The data are summarized in Table IV and Fig. 3 and show a significant fall $\vec{c}$ in mitral diastolic gradient, pulmonary capillary wedge pressure, and mean pulmonary arterial pressure. There was still a small residual gradient $\vec{\varphi}$ across the valve and the pulmonary arterial pressure did not return to normal.

LATE HAEMODYNAMIC STUDIES Nine patients were studied 4 months or more after valvotomy. The study was undertaken to assess important residual $\stackrel{\circ}{\mathbb{D}}$ disease in four (one with residual stenosis and three with mixed mitral valve disease), and five were studied electively to assess the status of the heart and pulmonary circulation. The latter five have been analysed in detail and their results are summarized in Table IV. There was a significant decrease in mitral diastolic gradient and pulmonary capillary wedge pressure. For a given PCWP this group of patients had a lower PAP than patients in the previous group. The two postoperative groups are not strictly comparable but the results suggest that mitral stenosis is not relieved completely by what appears to be an ade- $\frac{9}{3}$ quate valvotomy; pulmonary arterial pressure $\frac{?}{0}$ falls immediately after valvotomy and there is a further fall in subsequent months.

\section{DISCUSSION}

Mitral stenosis, as seen in Natal, resembles the $\omega$ disease as it was seen in the United States and in Great Britain in 1930 (Bland, White, and Jones,

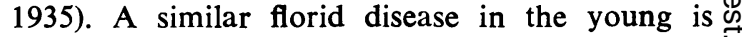
encountered in Israel (Borman et al., 1961), Italy (Reale, Colella, and Bruno, 1963), South India ơ (Cherian, Vytilingam, Sukumar, and Gopinath, $\overrightarrow{\mathbb{\Phi}}$

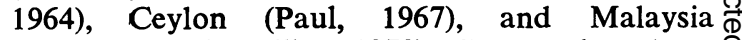
(Krishnan and Snelling, 1970). These authors have 응 highlighted the problems of mitral stenosis in childhood-the severe obstruction, the incidence 
of severe pulmonary arterial hypertension, the importance of haemoptysis as a presenting symptom, the incidence of premature calcification of the valve, and the fatal outcome if untreated.

We have no information about aetiology. Only two patients gave a history of acute rheumatic fever. This is in contrast with a similar group of 70 patients with severe rheumatic mitral incompetence in whom a previous history or other evidence of acute rheumatic carditis was present in four-fifths. The pathological anatomy of the valve was not significantly different from that of a comparable group of adult patients who needed mitral valvotomy. No patient had congenital mitral stenosis. Underlying rheumatic fever is likely but not proven. Regular biopsies of the atrial appendage were not taken.

Our experience demonstrates that the disease is severe in childhood and that critical mitral stenosis occurs frequently in this age group. There is an accelerated clinical course, dyspnoea is common, haemoptysis may be frightening, pulmonary hypertension and functional tricuspid incompetence are a consequence of severe obstruction, and atrial fibrillation is rare. The diagnosis is readily made at the bedside and the clinical picture does not differ from that seen in the adult. Functional tricuspid incompetence, a consequence of severe pulmonary arterial hypertension, may mask the picture of pure mitral stenosis and suggest additional mitral incompetence. Pulmonary arterial hypertension is severe and is a consequence of critical valve obstruction; it is partly passive and partly vasoconstrictive.

Valvotomy is rewarding provided it is undertaken in patients with mobile valve cusps and a competent valve. Calcification, or severe valve fibrosis with a jet of mitral incompetence, when they occur in this age group, suggest that the valve cusps are rigid and the seat of advanced fibrosis so that the result of valvotomy is usually unsatisfactory. In this group of patients, preliminary cardiac catheterization is essential and digital ex- ploration of the valve is necessary. The valve should be replaced if the lesion found at operation makes a good surgical result unlikely.

Pulmonary arterial pressure falls rapidly after a successful valvotomy. An immediate fall occurs in the week or two after operation and this fall continues thereafter, presumably consequent upon a decrease in vasoconstriction.

\section{REFERENCES}

Bland, E. F., White, P. D., and Jones, T. D. (1935). The development of mitral stenosis in young people, with a discussion of the frequent misinterpretation of a middiastolic murmur at the cardiac apex. American Heart Journal, 10, 995.

Borman, J. B., Stern, S., Shapira, T., Milwidsky, H. and Braun, K. (1961). Mitral valvotomy in children. American Heart Journal, 61, 763.

Cherian, G., Vytilingam, K. I., Sukumar, I. P., and Gopinath, N. (1964). Mitral valvotomy in young patients. British Heart Journal, 26, 157.

Ellis, L. B., Harken, D. E., and Black, H. (1959). A clinical study of 1000 consecutive cases of mitral stenosis two to nine years after mitral valvuloplasty. Circulation, 19, 803.

Harris, P., and Heath, D. (1962). The Human Pulmonary Circulation. Its Form and Function in Health and Disease, Ch. 13. Livingstone, Edinburgh and London.

Kitchin, A., and Turner, R. (1967). Calcification of the mitral valve. Results of valvotomy in 100 cases. British Heart Journal, 29, 137.

Krishnan, M., and Snelling, M. R. J. (1970). Mitral valvotomy in Malaysian patients of 20 years of age and below. Medical Journal of Malaya, 25, 105.

Logan, A., Lowther, C. P., and Turner, R. W. D. (1962). Reoperation for mitral stenosis. Lancet, 1, 443.

Paul, A. T. S. (1967). The problem of mitral stenosis in childhood. Annals of the Royal College of Surgeons of England, 41, 387.

Reale, A., Colella, C., and Bruno, A. M. (1963). Mitral stenosis in childhood: clinical and therapeutic aspects. American Heart Journal, 66, 15.

Turner, R. W. D. (1967). Surgery of the mitral valve. British Heart Journal, 29, 641.

— and Fraser, H. R. L. (1956). Mitral valvotomy. A progress report. Lancet, 2, 525 and 587. 